\title{
Análise Bibliométrica das Pesquisas em Contabilidade Gerencial que utilizaram a Estratégia do Estudo de Caso
}

\begin{abstract}
Lua Syrma Zaniah Santos
Mestrado em andamento em Controladoria e Contabilidade pela Universidade Federal de Minas Gerais - UFMG Estágio docente na Universidade Federal de Minas Gerais - UFMG Av. Pres. Antônio Carlos, 6627. Pampulha. Belo Horizonte/MG. CEP: 31270-901

E-mail: luasyrma@gmail.com
\end{abstract}

Juliana Ribeiro Souza Mestrado em andamento em Controladoria e Contabilidade pela Universidade Federal de Minas Gerais - UFMG E-mail: julianaribeiro.jrs@gmail.com

Weverton Eugenio Coelho Mestrado em andamento em Controladoria e Contabilidade pela Universidade Federal de Minas Gerais - UFMG Assistente em Administração na Universidade Federal de Minas Gerais - UFMG Av. Pres. Antônio Carlos, 6627. Pampulha. Belo Horizonte/MG. CEP: 31270-901 E-mail: wevertonecoelho@gmail.com

João Estêvão Barbosa Neto Doutorado em Controladoria e Contabilidade pela Universidade de São Paulo - USP Professor na Universidade Federal de Minas Gerais - UFMG Av. Pres. Antônio Carlos, 6627. Pampulha. Belo Horizonte/MG. CEP: 31270-901 E-mail: joaoestevaobarbosaneto@gmail.com

\section{RESUMO}

O Estudo de Caso é considerado uma estratégia de pesquisa apropriada para ser utilizada na Contabilidade Gerencial, pois foca no entendimento do dinamismo presente dentro da realidade, combinando método de coleta com as observações teóricas realizadas. Nesse sentido, este estudo teve como objetivo identificar as características bibliométricas dos artigos nacionais que utilizaram a estratégia de Estudo de Caso em pesquisas na área de Contabilidade Gerencial. A amostra foi composta por 593 artigos de Contabilidade Gerencial que obtiveram conceitos A2, B1 e B2 na classificação do Qualis CAPES entre os anos 2008 e 2016. Por meio dos resultados, verificou-se que, de um total de 593 artigos de Contabilidade Nacional, em 143 deles houve a utilização da metodologia de Estudo de Caso. Entre as pesquisas que fizeram uso desse método, os temas sobre Gestão Estratégica de Custos, Sistemas de Controle Gerencial e Balanced Scorecard se destacaram. Observou-se também que $79 \%$ desses trabalhos utilizaram o estudo de caso único. Nesse sentido, observa-se que há a necessidade de investigações adicionais, pois o Estudo de Caso demonstra potencialidade e adequações para os temas contábeis-gerenciais. 
Análise Bibliométrica das Pesquisas em Contabilidade Gerencial que utilizaram a Estratégia do Custeio de Caso

Lua Syrma Zaniah Santos, Juliana Ribeiro Souza, Weverton Eugenio Coelho, João Estêvão Barbosa

Palavras-chave: Contabilidade Gerencial. Bibliometria. Estudo de Caso.

\title{
Bibliometric Analysis of Research in Management Accounting: Characteristics of Articles that use a case study strategy
}

\begin{abstract}
The Case Study is an adequate research strategy to be applied in Managerial Accounting, since the understanding environment presents itself within reality, combining the method of data collection with the observations made. This article is not intended to be exhaustive. The sample was made up of 593 Management Accounting articles that obtained concepts A2, B1 and B2 in the Qualis CAPES classification between 2008 and 2016. Through the results, it was verified that out of a total of 593 National Accounting articles, in 143 they had a use of the Case methodology. Among the researches that make use of such methods, the Strategic Management Systems of Costs, Management Control Systems and Balanced Scorecard stood out. It was also observed that $79 \%$ of the papers used the single case study. In this sense, it is observed that there is a need for additional investigations, to study cases of potentialities and adequations for accounting-managerial issues.
\end{abstract}

Keywords: Management Accounting. Bibliometrics. Case study.

\section{INTRODUÇÃO}

A Contabilidade Gerencial surgiu em resposta às necessidades dos usuários internos, tendo como objetivo fornecer informações úteis à tomada de decisão dos gestores (Cruz, Espejo, Gassner, \& Walter, 2010). Nesse sentido, segundo Lopes e Lima (2001), as motivações organizacionais, como a demanda por novas técnicas e teorias que garantissem melhor condução das organizações, proporcionaram, a partir da década de 1960, ênfase nas pesquisas em Contabilidade Gerencial.

Segundo Frezatti, Nascimento e Junqueira (2009), "a miríade de problemas encontrados na pesquisa em Contabilidade Gerencial demanda uma multiplicidade de enfoques e visões para o entendimento da plenitude de seu objeto de estudo". Nessa perspectiva, como as organizações passam por diversas mudanças decorrentes do 
Análise Bibliométrica das Pesquisas em Contabilidade Gerencial que utilizaram a Estratégia do Custeio de Caso

Lua Syrma Zaniah Santos, Juliana Ribeiro Souza, Weverton Eugenio Coelho, João Estêvão Barbosa

ambiente competitivo e do surgimento de novas tecnologias, a utilização de estudos de campo permite a obtenção de profundidade nas análises, proporcionando maiores alternativas de conclusão sobre objetos relacionados dentro de realidades e contextos similares (Beuren \& Erfurth, 2010).

Com relação às estratégias de pesquisa na Contabilidade Gerencial, Beuren e Hall (2014) defendem que o Estudo de Caso aplicado à Contabilidade Gerencial pode ser um estudo qualitativo com abordagem profundamente teórica, uma vez que pouco se conhece dos aspectos internos das organizações. Desta maneira, parte das pesquisas em Contabilidade Gerencial é conduzida por meio de Estudos de Caso (Ahrens \& Dent, 1998), pois este método é capaz de demonstrar, com maior riqueza de detalhes, aspectos do funcionamento e do papel desempenhado pela Contabilidade Gerencial nas empresas (Beuren \& Hall, 2014).

Dado que essa área da Contabilidade opera em campo realístico, o Estudo de Caso é uma estratégia de pesquisa apropriada para ser utilizada, pois foca no entendimento do dinamismo presente dentro da realidade, combinando método de coleta (que pode ser qualitativo, quantitativo etc.) com as observações teóricas realizadas (Consoli, Scare, Fava \& Fratantonio, 2008).

Nesse contexto, Beuren e Hall (2014) identificaram o perfil dos artigos que utilizaram ou se referiram à estratégia do Estudo de Caso em pesquisas sobre a prática da Contabilidade Gerencial publicados em periódicos internacionais em Língua Inglesa, no período de 1962 a 2012. Os resultados demonstraram que "as publicações de artigos desenvolvidos por meio de Estudo de Caso em Contabilidade Gerencial tiveram um crescimento no decorrer dos anos analisados, mas com alta concentração em poucos periódicos. A maioria dos artigos relatou estudos empíricos, seguindo-se teóricos e os bibliométricos" (Beuren \& Hall, 2014).

Diante desses resultados, fez-se pensar quais seriam, em âmbito nacional, as características das pesquisas relativas à Contabilidade Gerencial que utilizaram o Estudo de Caso. Nesse sentido e diante do exposto, depara-se com a seguinte questão 
Análise Bibliométrica das Pesquisas em Contabilidade Gerencial que utilizaram a Estratégia do Custeio de Caso

Lua Syrma Zaniah Santos, Juliana Ribeiro Souza, Weverton Eugenio Coelho, João Estêvão Barbosa

de pesquisa: Quais as características bibliométricas dos artigos que empregaram a estratégia de Estudo de Caso em pesquisas na área de Contabilidade Gerencial no Brasil? Assim, o objetivo deste estudo consiste em identificar as características bibliométricas dos artigos publicados em periódicos nacionais que se utilizaram da estratégia de Estudo de Caso em pesquisas na área de Contabilidade Gerencial. Especificamente, buscou-se identificar a quantidade de artigos de Contabilidade Gerencial que utilizaram o Estudo de Caso como método; identificar quais os temas e assuntos mais recorrentes nessas pesquisas e quais os autores mais prolíficos.

Os resultados da presente pesquisa poderão subsidiar o conhecimento sobre periódicos editados no Brasil, especificamente aqueles com publicações em Contabilidade Gerencial que utilizaram o método de Estudo de Caso. Verifica-se que a pesquisa científica pode ser um meio para a formação de profissionais da área de Contabilidade Gerencial, contribuindo também para a disseminação desse conhecimento. Saber quanto, quais e como as pesquisas nacionais em Contabilidade Gerencial utilizam o Estudo de Caso pode proporcionar a troca de conhecimentos e informações entre profissionais e pesquisadores, de forma a proporcionar novas possibilidades de desenvolvimento científico e técnico em contabilidade. Também pode haver o aumento do entendimento sobre acontecimentos reais e contemporâneos dentro das organizações, contribuindo para a melhor compreensão dos fenômenos estudados.

A importância do presente estudo se encontra na necessidade de conhecer e avaliar a produtividade e a qualidade da pesquisa dos atores (autores/pesquisadores), permitindo identificar grupos e áreas de excelência acadêmica. Também contribuirá no tocante ao delineamento que fará do perfil de uso do Estudo de Caso em periódicos, colaborando assim para que eles vislumbrem se essa estratégia de pesquisa é bem aceita em publicações em Contabilidade Gerencial, apesar das diversas críticas à sua escassez de generalização (Yin, 2001). Por fim, para a ciência e, conforme Beuren e Hall (2014), um bom estudo em pesquisas de Contabilidade Gerencial pode gerar 
Análise Bibliométrica das Pesquisas em Contabilidade Gerencial que utilizaram a Estratégia do Custeio de Caso

Lua Syrma Zaniah Santos, Juliana Ribeiro Souza, Weverton Eugenio Coelho, João Estêvão Barbosa

inovações em técnicas contábeis e gerenciais.

\section{REVISÃO DE LITERATURA}

\subsection{Pesquisa em Contabilidade Gerencial}

A Contabilidade Gerencial tem seus objetivos alinhados aos da Contabilidade de forma geral, ou seja, auxiliar no processo de tomada de decisões relativas ao controle e à gestão do patrimônio das organizações, independentemente de seu porte ou área de atuação econômica (Cardoso, Mário, \& Aquino, 2007).

Porém, apesar de seu crescente papel nas organizações, a Contabilidade Gerencial vive constantemente tentando resolver um de seus maiores desafios: o paradoxo existente entre seu desenvolvimento teórico e a prática dessas ferramentas. Diversos autores chamaram a atenção para este problema, como Otley (1985), Johnson e Kaplan (1987), Green e Amenkhienan (1992), Drury e Tayles (1995) e Granlund (2001). Tais autores observaram que o desenvolvimento de novas técnicas de controle gerencial tem gerado poucos efeitos, na prática, nas organizações.

No ambiente internacional, o estado da arte de pesquisas em Contabilidade Gerencial foi analisado, entre outros autores, por Ittner e Lacker (2001) e Zimmerman (2001), cujos estudos geraram discussões a respeito do tema, por apresentarem diferentes pontos de vista e, principalmente, pelo fato de Zimmerman (2001) construir seus argumentos e críticas tendo por base os pontos expostos por Ittner e Lacker (2001). Estes últimos discutiram a situação das pesquisas em Contabilidade Gerencial, considerando aspectos metodológicos e teóricos por meio da gestão baseada no valor, que inclui ferramentas como o Custeio $A B C$ e o Balanced Scorecard, e estratégias de pesquisa do tipo survey. Entre as conclusões, apontou-se que a pesquisa em Contabilidade Gerencial não tem aprofundado os tópicos estudados por não apresentar diferenças nas abordagens, pela baixa condição de publicação e pela dificuldade de se obter dados para a realização das pesquisas. 
Análise Bibliométrica das Pesquisas em Contabilidade Gerencial que utilizaram a Estratégia do Custeio de Caso

Lua Syrma Zaniah Santos, Juliana Ribeiro Souza, Weverton Eugenio Coelho, João Estêvão Barbosa

Zimmermean (2001), por sua vez, aponta que Ittner e Lacker (2001) citaram pequenas quantidades de artigos para embasar seus achados, caracterizados, em sua maioria, como práticos e que estavam longe de se utilizar de teorias econômicas para explicar os fenômenos contábeis, ou seja, do monoparadigma econômico. Dessa forma, Zimmermean (2001) construiu seus argumentos sob a luz desse monoparadigma, evidenciando que a pesquisa em Contabilidade Gerencial não se desenvolveu porque os estudos realizados não possuem chances de se tornar uma teoria generalizada (Frezatti et al., 2009).

Segundo Frezatti et al. (2009), esse contraponto entre as referidas pesquisas foi muito útil para levantar discussões sobre o desenvolvimento da Contabilidade Gerencial e suas especificidades e o interesse dos periódicos. Ainda, conforme os autores, os pesquisadores devem estar dispostos a entender a alternativa de constructo que proporcione uma solução satisfatória para o momento, pois muito do que se pesquisa em Contabilidade Gerencial ainda necessita de melhorias na qualidade metodológica.

No ambiente nacional, Cruz et al. (2010) analisaram o desenvolvimento do campo de pesquisa em Contabilidade Gerencial, considerando a perspectiva colaborativa mapeada em redes sociais no período de 2004 a 2008. Identificaram, em relação às instituições de ensino, que os principais agentes do campo consistem, principalmente, na USP-SP, bem como na UFMG, UFPE e UFPR. Entre os autores, Antônio A. de Souza se manteve como central no período de 2005-2007, sendo que outros autores também se destacaram em cada período.

Nascimento, Junqueira e Martins (2010) desenvolveram um estudo sobre as características epistemológicas da produção acadêmica da pesquisa em Contabilidade Gerencial no Brasil. Analisaram os trabalhos publicados nos congressos da Associação Nacional de Programas de Pós-Graduação em Ciências Contábeis (Anpcont) de 2007 e 2008, Congressos de Contabilidade e Controladoria da USP e os Encontros da Associação Nacional de Pós-Graduação e Pesquisa em Administração (Anpad) dos anos 2005 a 2008, em um total de 287 trabalhos. Os resultados indicaram: baixa utilização 
Análise Bibliométrica das Pesquisas em Contabilidade Gerencial que utilizaram a Estratégia do Custeio de Caso

Lua Syrma Zaniah Santos, Juliana Ribeiro Souza, Weverton Eugenio Coelho, João Estêvão Barbosa

de referências que abordem as teorias da Contabilidade Gerencial, baixa incidência de referências a artigos publicados em periódicos internacionais e alta idade média dos trabalhos citados (10 anos). As estratégias de pesquisa se concentram em pesquisas de campo, levantamentos descritivos ou trabalhos documentais, sem geração de teorias substantivas ou trabalhos de natureza explicativa.

Já Lunkes, Rosa, Gasparetto e Baldoino (2011) examinaram a produção científica e a formação de doutores em Contabilidade Gerencial no cenário brasileiro. Utilizaram sete revistas brasileiras de Contabilidade, segundo o Qualis CAPES no período de 2001 a 2010; e as teses de doutorado em Contabilidade da Universidade de São Paulo (USP) no período de 1962 a 2010. Verificaram um crescimento das publicações no início do período analisado e um leve decréscimo nos últimos três anos. Observaram também que a formação de doutores em Contabilidade Gerencial teve um aumento no período, o que seria um reflexo do crescimento na formação de doutores em Contabilidade no período analisado.

Por fim, Frezatti, Aguiar, Wanderley e Malaguenõ (2015) investigaram a pesquisa em Contabilidade Gerencial sob as perspectivas do desenvolvimento, das dificuldades e das oportunidades. Eles realizaram uma análise do I Encontro de Docentes de Contabilidade Gerencial/Controle Gerencial promovido pela Faculdade de Economia, Administração e Contabilidade da Universidade de São Paulo (FEA-USP), para discutir o desenvolvimento desta área no país. Por meio de algumas reflexões, os autores fizeram diversas constatações sobre o status quo da pesquisa brasileira em Contabilidade Gerencial. Eles chegaram à conclusão de que os temas que mais prevalecem nas pesquisas nacionais são orçamento e controle gerencial, o que pode indicar que o entendimento de contabilidade gerencial é restrito a esses temas.

Referente aos problemas encontrados na Contabilidade Gerencial, os autores refletiram que o reduzido número de doutores na área evidencia a pouca tradição em pesquisas na área. Em contraponto, devido ao crescimento do número de publicações, o grau de dificuldade para publicação aumentou, o que em consequência gerou uma 
Análise Bibliométrica das Pesquisas em Contabilidade Gerencial que utilizaram a Estratégia do Custeio de Caso

Lua Syrma Zaniah Santos, Juliana Ribeiro Souza, Weverton Eugenio Coelho, João Estêvão Barbosa

pressão por artigos de melhor qualidade teórica e das análises empíricas. Por fim, constataram uma lacuna entre as pesquisas e a prática de Contabilidade Gerencial e, sendo assim, sugeriram uma maior integração entre a prática e o conteúdo das pesquisas de forma a ser capaz de gerar contribuições teórico-práticas à comunidade científica nacional e internacional.

Diante desse contexto, Hopwood (2007) exorta que é preciso voltar a desenvolver um conhecimento atual em Contabilidade, visto que deve aproximar-se mais das organizações, onde é possível perceber a prática da gestão e o papel da Contabilidade. Segundo Nascimento et al. (2010: 1128), "questões relacionadas a desempenho, governança, accountability, risco, questões humanas, sociais e ambientais relacionadas ao estudo do controle, entre outras, podem contribuir efetivamente para situar a pesquisa em Contabilidade Gerencial em um amplo debate público, aumentando a sua relevância para a sociedade".

\subsection{Estudo de Caso e sua relevância para pesquisa em Contabilidade Gerencial}

Cada vez mais se utiliza a metodologia de Estudo de Caso para pesquisas científicas por suas características específicas (Yin, 2001, Martins \& Theófilo, 2009). Essa metodologia é uma estratégia de pesquisa que investiga um fenômeno dentro do seu contexto real quando os limites entre fenômeno e contexto não são claramente definidos, permitindo a compreensão de fenômenos complexos de forma mais detalhada (Yin, 2001).

Ele pode ser utilizado para documentar um acontecimento com apresentação rigorosa dos dados empíricos, com fundamentos lógicos, não sendo, dessa forma, meramente uma coleta de evidências, mas, sim, de trazer os antecedentes e razões para os eventos observados, contribuindo para o entendimento dos fenômenos individuais, organizacionais dentre outros (Graham, 2010; Yin, 2001).

Nesse sentido, Beuren e Hall (2014) enunciam que "o Estudo de Caso é um método capaz de demonstrar, com maior riqueza de detalhes, aspectos do 
Análise Bibliométrica das Pesquisas em Contabilidade Gerencial que utilizaram a Estratégia do Custeio de Caso

Lua Syrma Zaniah Santos, Juliana Ribeiro Souza, Weverton Eugenio Coelho, João Estêvão Barbosa

funcionamento e do papel desempenhado pela Contabilidade Gerencial nas organizações". E, ainda conforme os autores, como essa estratégia permite aprofundar observações do cotidiano in loco, pesquisas dessa natureza são relevantes à diversidade do conhecimento dessa área.

O Estudo de Caso é uma estratégia de pesquisa apropriada para ser utilizada em pesquisas de Contabilidade Gerencial, porque foca no entendimento do dinamismo presente dentro da realidade, combinando método de coleta (que pode ser qualitativo, quantitativo etc.) com as observações teóricas realizadas (Consoli et al., 2008).

Muitas vezes, a Contabilidade nas organizações caracteriza-se por ambiguidades e por formas contraditórias de gestão, o que resulta em diferentes contextos organizacionais (Ahrens \& Dent, 1998). Hopwood (1983) e Kaplan (1984) lideraram uma discussão na literatura, na década de 1980, para a ampliação dos estudos de campo em Contabilidade, dada a necessidade de se conhecer como as técnicas contábeis têm sido utilizadas nas organizações (Beuren \& Hall, 2014).

No entanto, dada a pequena abrangência dos resultados ao restringir o estudo a um ou poucos casos, a utilidade do método do Estudo de Caso em pesquisas de Contabilidade Gerencial encontra controvérsias na literatura (Beuren \& Hall, 2014). A maioria das críticas diz respeito às dificuldades de generalização dos resultados. Entretanto, Yin (2001) explica que as limitações para generalização podem decorrer da incorreta aplicação da estratégia de pesquisa Estudo de Caso.

Assim sendo, Alves (2006) evidenciou que o problema dos trabalhos denominados Estudos de Caso não se caracterizam como tal, mas, sim, refletem um erro de pesquisadores que acreditam que devem assim denominá-los apenas por serem desenvolvidos em uma única unidade. Dessa forma, Cesar e Antunes (2008) identificaram, entre os problemas de utilização do Estudo de Caso, o fato de os pesquisadores não buscarem confirmação de evidências, não seguirem um protocolo de pesquisa e não usarem critérios que justifiquem a escolha dos casos estudados.

Mas, apesar dessas controvérsias, estudos como o de Faria, Leal, Soares e 
Análise Bibliométrica das Pesquisas em Contabilidade Gerencial que utilizaram a Estratégia do Custeio de Caso

Lua Syrma Zaniah Santos, Juliana Ribeiro Souza, Weverton Eugenio Coelho, João Estêvão Barbosa

Godoi-de-Sousa (2013) evidenciam significativa adoção de Estudo de Casos em pesquisas relativas à Contabilidade Gerencial. No intuito de identificar, descrever e analisar as principais características da produção científica em Contabilidade Gerencial publicada nos periódicos nacionais na área contábil, o estudo apontou que as estratégias mais utilizadas pelos pesquisadores foram a pesquisa bibliográfica e o Estudo de Caso, sendo este último mais usado se comparado à tipologia com o tipo de metodologia empregada.

Nesta conjuntura, o Estudo de Caso se mostra como uma importante ferramenta para auxiliar o desenvolvimento de pesquisas acerca da realidade das organizações em seus contextos, de maneira aprofundada, possibilitando que os gestores possam conhecer melhor o ambiente organizacional e as variáveis que se relacionam com este meio, afim de que possam usufruir, com maior aderência, de toda a gama conceitual e das técnicas que compõem a Contabilidade Gerencial.

\subsection{Estudos empíricos anteriores}

Em consonância com o que foi realizado no presente estudo, procurou-se fazer uma análise de pesquisas semelhantes já realizadas. Neste sentido, apresentam-se, neste tópico, os principais estudos e suas contribuições para a caracterização do perfil das pesquisas na área de Contabilidade Gerencial.

Consoli et al. (2008) discutiram a utilização de estudos de caso como método de pesquisa nas áreas gerenciais, destacadamente a administração de empresas e engenharia de produção. Constataram, ao analisarem pesquisas publicadas em congressos e eventos no período de 2003 a 2007, a concentração de estudos com propósito descritivo e exploratório com estruturas comparativas e lineares e poucos exemplares de pesquisas para desenvolvimento e proposições de teorias e modelos a partir de estudos de caso. Além disso, discutiram como a falta de rigor metodológico e planejamento da pesquisa com Estudo de Casos, desde a seleção dos casos até o fechamento e relatórios, reduzem as vantagens desse método e a validade da 
Análise Bibliométrica das Pesquisas em Contabilidade Gerencial que utilizaram a Estratégia do Custeio de Caso

Lua Syrma Zaniah Santos, Juliana Ribeiro Souza, Weverton Eugenio Coelho, João Estêvão Barbosa

pesquisa.

Oliveira e Boente (2012) realizaram uma análise bibliométrica da produção científica recente sobre a Contabilidade Gerencial com o objetivo de descrever e analisar as principais características do perfil da produção na área. Verificaram que predominou, entre os estudos, a pesquisa exploratória e que o Estado de São Paulo foi a maior localidade de produção científica e equilíbrio na utilização de referências nacionais e internacionais por artigo.

Faria et al. (2013) buscaram identificar, descrever e analisar as principais características da produção científica em Contabilidade Gerencial publicada nos periódicos nacionais, na área contábil, no período de 2002 a 2012, tendo como ferramenta de pesquisa a bibliometria. $O$ estudo apontou que as estratégias mais utilizadas pelos pesquisadores foram a pesquisa bibliográfica e o Estudo de Caso, sendo este último mais usado se comparado à tipologia com o tipo de metodologia empregada.

Marques, Camacho e Alcantara (2015) avaliaram o rigor metodológico dos estudos de caso em Contabilidade Gerencial publicados em periódicos no Brasil, no período de 2008 a 2012, classificados como A2, B1 e B2. Os autores desenvolveram, com base na literatura, um conjunto de 15 quesitos para avaliar se os estudos de caso poderiam ser considerados adequados sob o ponto de vista do rigor metodológico. Concluíram que é necessário melhorar a forma com que os estudos de caso são empregados na Contabilidade Gerencial, pois foram poucos os trabalhos caracterizados pela aplicação rigorosa dos procedimentos relativos a essa estratégia.

Adicionalmente, o estudo de Carvalho, Pierri Júnior, Lunkes e Gasparetto (2016) objetivou identificar e analisar o perfil das publicações com o tema Contabilidade Gerencial em periódicos internacionais de contabilidade, indexados ao banco de dados ISI (Institute for Scientific Information). Após a análise que abrangeu o período de 2001 a 2015, os autores concluíram que o método mais utilizado nos estudos analisados foi o estudo de caso, sendo o Controle Organizacional o tema predominante nas 
Análise Bibliométrica das Pesquisas em Contabilidade Gerencial que utilizaram a Estratégia do Custeio de Caso

Lua Syrma Zaniah Santos, Juliana Ribeiro Souza, Weverton Eugenio Coelho, João Estêvão Barbosa

investigações.

Indo na mesma direção, Ribeiro e Tavares (2017) analisaram o comportamento e as características da produção acadêmica referente à área contábil-gerencial divulgada também na base ISI, mas, considerando o período de 1985 a 2014 e os resultados, apontaram para uma evolução da temática a partir de 2007 e evidenciaram que os temas: educação; ensino e pesquisa contábil; gestão de custos; controle de gestão; gestão estratégica e sistema de contabilidade gerencial obtiveram destaque.

Por fim, Blonkoski, Antonelli e Bortoluzzi (2017) exploraram a situação atual de desenvolvimento da contabilidade gerencial considerando o viés da comunidade científica e empregando o instrumento de pesquisa Proknow- $C$ para seleção dos artigos e análises bibliométrica e sistêmica. Dentre os resultados, identificaram que, na maioria dos estudos analisados, o enquadramento metodológico não é explicitado e que as principais teorias e conceitos utilizados foram planejamento estratégico, sistemas de informações gerenciais, teoria da prática e teoria institucional.

Observa-se, assim, uma vasta literatura referente à análise de artigos de Contabilidade Gerencial sob diferentes aspectos e diferentes metodologias, o que, além de confirmar a importância do tema tratado, delineia a possibilidade de comparação entre os estudos já tratados e o presente, além de fornecer base e contribuições para a análise.

\section{MÉTODO}

O presente estudo caracteriza-se, quanto aos objetivos, como pesquisa descritiva, visto que descreve as características dos artigos publicados em periódicos nacionais, referentes à Contabilidade Gerencial, que utilizaram a estratégia do Estudo de Caso como metodologia de pesquisa. Além disso, o estudo apresenta-se como uma pesquisa bibliométrica, visto que, no intuito de avaliar a produção científica para mapear e conhecer os trabalhos acadêmicos divulgados nos periódicos analisados, utilizou-se 
Análise Bibliométrica das Pesquisas em Contabilidade Gerencial que utilizaram a Estratégia do Custeio de Caso

Lua Syrma Zaniah Santos, Juliana Ribeiro Souza, Weverton Eugenio Coelho, João Estêvão Barbosa

da técnica de bibliometria.

Segundo Moraes, Igarashi, Camacho e Marques (2013), as pesquisas bibliométricas vêm sendo utilizadas com frequência em estudos publicados nos periódicos nacionais, pois permitem que se realize uma análise da produção científica de uma determinada área, dando sustentação à produção de novos trabalhos. A bibliometria, dessa forma, torna-se um "recurso fundamental na difusão da produção científica, alcançando sua finalidade através de uma técnica capaz de medir a influência de pesquisadores ou periódicos, tornando possível traçar o perfil dos mesmos e suas tendências, assim como evidenciar áreas temáticas, entre outros" (Oliveira, Barbosa, Rezende, Silva e Albuquerque et al., 2013).

A amostra do estudo é composta pelos artigos da área de Contabilidade Gerencial que foram publicados em periódicos nacionais, que obtiveram conceitos A2, B1 e B2 na classificação da Coordenação de Aperfeiçoamento de Pessoal de Nível Superior (CAPES), por meio do programa Qualis, no período abrangido entre os anos 2008 e 2016. Destaca-se que a classificação A1 não foi utilizada no estudo, pois nenhum periódico nacional constava com essa avaliação na base de dados da CAPES até o mês de março de 2016, período em que foram coletadas as informações relativas à classificação dos periódicos.

Para a seleção dos artigos, inicialmente avaliaram-se seus títulos a fim verificar se estavam relacionados com os temas da área Contabilidade Gerencial. Em caso de dúvida, analisaram-se as palavras-chave e, por último, o resumo. Foram identificados 26 periódicos nacionais que publicam artigos na área de Contabilidade. Nesses periódicos, encontrou-se um total de 593 artigos relativos a pesquisas no campo da Contabilidade Gerencial.

Após a seleção, os artigos foram categorizados de acordo com a classificação do periódico no Qualis CAPES, o ano de publicação, a metodologia de estudo empregada (Estudo de Caso único, múltiplo ou outro tipo de metodologia) e assunto abordado. Assim, para chegarem aos artigos finais, após a seleção dos periódicos, os 
Análise Bibliométrica das Pesquisas em Contabilidade Gerencial que utilizaram a Estratégia do Custeio de Caso

Lua Syrma Zaniah Santos, Juliana Ribeiro Souza, Weverton Eugenio Coelho, João Estêvão Barbosa

Neto

pesquisadores observaram, em livros de Contabilidade Gerencial, os temas mais abordados pela literatura. Após esses procedimentos, a amostra final ficou composta por 143 trabalhos.

As características bibliométricas utilizadas foram: quantidade de artigos de Contabilidade Gerencial que utilizaram o Estudo de Caso como método; quais os temas e assuntos mais recorrentes nessas pesquisas; e quais os autores mais prolíferos. Por meio do Quadro 1, é possível verificar as etapas seguidas pelos autores para a realização do estudo.

\begin{tabular}{|c|c|c|}
\hline 1ํ passo & Seleção de periódicos Qualis A2, B2 e B1. & 26 periódicos \\
\hline $2^{\circ}$ passo & Seleção de artigos publicados em periódicos Qualis A2, B2 e B1. & \multirow[b]{2}{*}{593 artigos } \\
\hline $3^{\circ}$ passo & $\begin{array}{l}\text { Análise dos títulos, palavras-chave e Resumo dos artigos, procurando-se } \\
\text { selecionar aqueles relacionados à área Contabilidade Gerencial. }\end{array}$ & \\
\hline $4^{\circ}$ passo & $\begin{array}{l}\text { Categorização dos artigos de acordo com a metodologia de estudo } \\
\text { empregada, selecionando aqueles em que foi utilizado o Estudo de Caso. }\end{array}$ & \multirow{4}{*}{143 artigos } \\
\hline $5^{\circ}$ passo & $\begin{array}{l}\text { Categorização dos artigos de acordo com a metodologia de estudo } \\
\text { empregada (Estudo de Caso único, múltiplo ou outro tipo de metodologia) } \\
\text { e assunto abordado. }\end{array}$ & \\
\hline $6^{\circ}$ passo & $\begin{array}{l}\text { Separação por temas de Contabilidade Gerencial abordados em livros, } \\
\text { tais como Gestão Estratégica de Custos, Sistemas de Controle Gerencial, } \\
\text { Balanced Scorecard, Orçamento, Incentivos Gerenciais, Folga } \\
\text { Orçamentária, Preço de Transferência, e Mudanças nas Práticas de } \\
\text { Contabilidade Gerencial. }\end{array}$ & \\
\hline $7^{\circ}$ passo & $\begin{array}{l}\text { Análise das características bibliométricas analisadas como: quantidade de } \\
\text { artigos de Contabilidade Gerencial que utilizaram o Estudo de Caso como } \\
\text { método; temas e assuntos mais recorrentes nessas pesquisas e quais os } \\
\text { autores mais prolíferos. }\end{array}$ & \\
\hline
\end{tabular}

Quadro 1. Passos metodológicos para a seleção da amostra e análise dos dados

Nota. Fonte: Elaborado pelos autores (2018).

\section{ANÁLISE DOS RESULTADOS}

\subsection{Perfil dos artigos publicados em periódicos classificados como A2}

Analisando as publicações nos periódicos classificados como A2, constatou-se que, no período analisado, 119 artigos foram publicados sobre os temas relativos à 
Análise Bibliométrica das Pesquisas em Contabilidade Gerencial que utilizaram a Estratégia do Custeio de Caso Lua Syrma Zaniah Santos, Juliana Ribeiro Souza, Weverton Eugenio Coelho, João Estêvão Barbosa Neto

área de Contabilidade Gerencial, como demonstrado na Tabela 1. Verificou-se que o periódico que mais realizou publicações nesse campo foi a revista Contabilidade Vista e Revista, responsável por 29\% das publicações, seguida pela Revista Universo Contábil, com $19 \%$, e a Revista Contabilidade e Finanças, que publicou $14 \%$ do total de artigos identificados.

Tabela 1

Publicações em periódicos classificados como A2

\begin{tabular}{|l|c|c|c|c|c|c|c|c|c|c|c|}
\hline \multicolumn{1}{|c|}{ Periódico } & $\mathbf{2 0 0 8}$ & $\mathbf{2 0 0 9}$ & $\mathbf{2 0 1 0}$ & $\mathbf{2 0 1 1}$ & $\mathbf{2 0 1 2}$ & $\mathbf{2 0 1 3}$ & $\mathbf{2 0 1 4}$ & $\mathbf{2 0 1 5}$ & $\mathbf{2 0 1 6}$ & Total & $\%$ \\
\hline $\begin{array}{l}\text { Contabilidade Vista e } \\
\text { Revista }\end{array}$ & 6 & 3 & 5 & 5 & 2 & 2 & 2 & 1 & 9 & 35 & $29 \%$ \\
\hline $\begin{array}{l}\text { Revista de Administração } \\
\text { Contemporânea - RAC }\end{array}$ & 3 & 2 & 1 & 1 & 1 & 1 & 2 & & 2 & 13 & $11 \%$ \\
\hline $\begin{array}{l}\text { Revista de Administração } \\
\text { de Empresas - RAE }\end{array}$ & 1 & 1 & & 1 & & 2 & & 1 & 6 & $5 \%$ \\
\hline $\begin{array}{l}\text { Revista de Administração } \\
\text { da USP - RAUSP }\end{array}$ & & & & 1 & & 1 & & & 2 & $2 \%$ \\
\hline $\begin{array}{l}\text { Revista Brasileira de } \\
\text { Gestão de Negócios }\end{array}$ & & 1 & 2 & 2 & 3 & 2 & 1 & & 11 & $9 \%$ \\
\hline $\begin{array}{l}\text { Revista Contabilidade e } \\
\text { Finanças }\end{array}$ & 4 & 4 & & 1 & 2 & 1 & 1 & 2 & 2 & 17 & $14 \%$ \\
\hline $\begin{array}{l}\text { Revista de Administração } \\
\text { Pública }\end{array}$ & 1 & 1 & 5 & 2 & 1 & 2 & & & & 12 & $10 \%$ \\
\hline Revista Universo Contábil & 3 & & 4 & 4 & 2 & 3 & 3 & 3 & 1 & 23 & $19 \%$ \\
\hline Total de artigos & 17 & 11 & 17 & 15 & 12 & 12 & 13 & 7 & 15 & $\mathbf{1 1 9}$ & $100 \%$ \\
\hline \multicolumn{1}{|c|}{$\%$} & $14 \%$ & $9 \%$ & $14 \%$ & $13 \%$ & $10 \%$ & $10 \%$ & $11 \%$ & $6 \%$ & $13 \%$ & $100 \%$ & \\
\hline
\end{tabular}

Nota. Fonte: elaborada pelos autores (2018).

Em relação ao período analisado, os anos 2008 e 2010 destacaram-se como aqueles em que houve mais publicações de artigos, correspondendo a 14\%, cada um, em relação ao total de publicações em periódicos A2. Verificou-se que não houve uma evolução constante no número de artigos publicados nesse campo de pesquisa ao longo do período. A quantidade de publicações em periódicos A2 que utilizaram a metodologia de Estudo de Caso está evidenciada na Tabela 2. 
Análise Bibliométrica das Pesquisas em Contabilidade Gerencial que utilizaram a Estratégia do

Custeio de Caso

Lua Syrma Zaniah Santos, Juliana Ribeiro Souza, Weverton Eugenio Coelho, João Estêvão Barbosa

\section{Tabela 2}

Publicações em periódicos A2 que utilizaram a metodologia de Estudo de Caso

\begin{tabular}{|c|c|c|c|c|c|c|c|c|c|c|c|c|}
\hline Periódico & $\begin{array}{c}\text { Estudo } \\
\text { de } \\
\text { Caso }\end{array}$ & 2008 & 2009 & 2010 & 2011 & 2012 & 2013 & 2014 & 2015 & 2016 & Total & $\begin{array}{l}\text { Estudo } \\
\text { de } \\
\text { Casos }\end{array}$ \\
\hline \multirow{2}{*}{$\begin{array}{l}\text { Contabilidade } \\
\text { Vista e Revista }\end{array}$} & Único & 2 & 1 & & & & & 1 & & 4 & 8 & \multirow{2}{*}{11} \\
\hline & Múltiplo & 1 & & 1 & 1 & & & & & & 3 & \\
\hline \multirow{2}{*}{$\begin{array}{l}\text { Revista de } \\
\text { Administração } \\
\text { Contemporânea - } \\
\text { RAC }\end{array}$} & Único & & & & 1 & 1 & & & & & 2 & \multirow[b]{2}{*}{4} \\
\hline & Múltiplo & 1 & 1 & & & & & & & & 2 & \\
\hline \multirow{2}{*}{$\begin{array}{ll}\text { Revista } & \text { de } \\
\text { Administração de } \\
\text { Empresas - RAE }\end{array}$} & Único & & & & & & & 1 & & & 1 & \multirow[b]{2}{*}{1} \\
\hline & Múltiplo & & & & & & & & & & 0 & \\
\hline \multirow{2}{*}{$\begin{array}{ll}\text { Revista } & \text { de } \\
\text { Administração } & \text { da } \\
\text { USP - RAUSP } & \end{array}$} & Único & & & & & & 1 & & & & 1 & \multirow[b]{2}{*}{1} \\
\hline & Múltiplo & & & & & & & & & & 0 & \\
\hline \multirow{2}{*}{$\begin{array}{l}\text { Revista Brasileira } \\
\text { de Gestão de } \\
\text { Negócios }\end{array}$} & Único & 1 & 2 & & & 1 & & & & 1 & 5 & \multirow[b]{2}{*}{6} \\
\hline & Múltiplo & 1 & & & & & & & & & 1 & \\
\hline \multirow{2}{*}{$\begin{array}{ll}\text { Revista } & \text { de } \\
\text { Administração } & \\
\text { Pública } & \end{array}$} & Único & & & 1 & 1 & & 2 & & & & 4 & \multirow[b]{2}{*}{5} \\
\hline & Múltiplo & & & & & 1 & & & & & 1 & \\
\hline \multirow{2}{*}{$\begin{array}{l}\text { Revista Universo } \\
\text { Contábil }\end{array}$} & Único & & & 1 & & 1 & 1 & 1 & 1 & 1 & 6 & \multirow{2}{*}{8} \\
\hline & Múltiplo & & & & & 1 & 1 & & & & 2 & \\
\hline Total de artigos & 6 & 4 & 3 & 3 & 5 & 5 & 3 & 1 & 6 & & 36 & \\
\hline
\end{tabular}

Nota. Fonte: elaborada pelos autores (2018).

Constatou-se que apenas 36 artigos, ou seja, 30\% do total adotaram o Estudo de Caso para a realização das pesquisas, sendo o Estudo de Caso único a tipologia mais adotada (Tabela 2). A revista Contabilidade Vista e Revista também se destacou como o periódico em que mais se publicam artigos que realizam Estudos de Caso, sendo essa metodologia adotada em 11 das suas 35 publicações. Novamente este periódico foi seguido pela Revista Universo Contábil, que publicou 8 artigos que adotaram Estudos de Caso, e pela Revista Contabilidade e Finanças em que 6 artigos empregaram essa metodologia. Salienta-se que o periódico Revista de Administração de Empresas - RAE não realizou nenhuma publicação que adotou a metodologia do 
Análise Bibliométrica das Pesquisas em Contabilidade Gerencial que utilizaram a Estratégia do Custeio de Caso

Lua Syrma Zaniah Santos, Juliana Ribeiro Souza, Weverton Eugenio Coelho, João Estêvão Barbosa

Estudo de Caso, único ou múltiplo, no período de 2008 a 2016.

Diante desses resultados, observou-se que não existe uma tendência de evolução, durante o período analisado, no número de artigos publicados que empregaram esta metodologia. $\mathrm{O}$ ano de 2015, por exemplo, apresentou apenas uma publicação que adotou o Estudo de Caso.

Dentre os artigos analisados, aqueles que não empregaram o Estudo de Caso como metodologia de pesquisa adotaram, em sua maioria, pesquisa de abordagem quantitativa, com realização de pesquisas descritivas, bibliográficas, documental e bibliométricas, e utilização de técnicas de levantamento ou survey e entrevistas.

Considerando os temas abordados na totalidade de publicações em periódicos A2 relativos ao campo de pesquisa em Contabilidade Gerencial, verificaram-se 38 estudos que analisaram temas relativos à Gestão Estratégica de Custos, 15 em relação a Sistemas de Controle Gerencial e 12 sobre Balanced Scorecard (BSC).

Especificamente em relação aos artigos que adotaram o Estudo de Caso, seja único ou múltiplo, constatou-se que 12 artigos analisaram assuntos relativos à Gestão Estratégica de Custos e 9 artigos referente a Sistemas de Controle Gerencial. Os assuntos explorados de forma esporádica por esses artigos foram: orçamento, incentivos gerenciais, folga orçamentária, preço de transferência e mudanças nas práticas de Contabilidade Gerencial.

\subsection{Perfil dos artigos publicados em periódicos classificados como B1}

Observou-se, para os periódicos classificados como B1, um total de 352 publicações na área de Contabilidade Gerencial. Neste contexto, a Revista Custos e Agronegócios Online e a Revista de Administração e Contabilidade da Unisinos se destacaram em relação às demais, obtendo 38\% e 19\% das publicações analisadas no período, respectivamente (Tabela 3). 
Análise Bibliométrica das Pesquisas em Contabilidade Gerencial que utilizaram a Estratégia do Custeio de Caso Lua Syrma Zaniah Santos, Juliana Ribeiro Souza, Weverton Eugenio Coelho, João Estêvão Barbosa

Tabela 3

Publicações em periódicos classificados como B1

\begin{tabular}{|l|c|c|c|c|c|c|c|c|c|c|c|}
\hline Periódico & $\mathbf{2 0 0 8}$ & $\mathbf{2 0 0 9}$ & $\mathbf{2 0 1 0}$ & $\mathbf{2 0 1 1}$ & $\mathbf{2 0 1 2}$ & $\mathbf{2 0 1 3}$ & $\mathbf{2 0 1 4}$ & $\mathbf{2 0 1 5}$ & $\mathbf{2 0 1 6}$ & Total & $\%$ \\
\hline $\begin{array}{l}\text { Rev. de Adm. e Contab. } \\
\text { da Unisinos }\end{array}$ & 7 & 8 & 5 & 8 & 5 & 9 & 9 & 9 & 7 & 67 & $19 \%$ \\
\hline $\begin{array}{l}\text { Brazilian Business } \\
\text { Review }\end{array}$ & 3 & 5 & 5 & 1 & 4 & 4 & 6 & 4 & 2 & 34 & $9 \%$ \\
\hline $\begin{array}{l}\text { Contabilidade, Gestão e } \\
\text { Governança }\end{array}$ & 4 & 4 & 3 & 4 & 4 & 4 & 5 & & 28 & $8 \%$ \\
\hline $\begin{array}{l}\text { Custos e Agronegócios } \\
\text { Online }\end{array}$ & 16 & 9 & 11 & 11 & 12 & 16 & 15 & 22 & 20 & 132 & $38 \%$ \\
\hline $\begin{array}{l}\text { Enfoque: Reflexão } \\
\text { Contábil }\end{array}$ & 5 & 4 & 1 & 1 & 1 & 2 & 4 & 4 & 4 & 26 & $9 \%$ \\
\hline $\begin{array}{l}\text { Revista de contabilidade } \\
\text { e Organizações }\end{array}$ & 4 & 4 & 6 & 6 & 3 & 2 & 3 & 2 & & 30 & $9 \%$ \\
\hline $\begin{array}{l}\text { Rev. de Contab. do } \\
\text { Mestrado em Ciências } \\
\text { Contábeis da UERJ }\end{array}$ & 1 & 7 & & 3 & 1 & 6 & 2 & 2 & 1 & 23 & $7 \%$ \\
\hline $\begin{array}{l}\text { Rev. de Educ. e Pesq. } \\
\text { em Contabilidade }\end{array}$ & & & 2 & & 2 & 3 & 3 & 2 & 12 & $3 \%$ \\
\hline Total de artigos & 36 & 41 & 32 & 35 & 30 & 45 & 46 & 51 & 36 & $\mathbf{3 5 2}$ & $100 \%$ \\
\hline \% & $10 \%$ & $12 \%$ & $9 \%$ & $10 \%$ & $9 \%$ & $13 \%$ & $13 \%$ & $14 \%$ & $10 \%$ & $100 \%$ & \\
\hline
\end{tabular}

Nota. Fonte: elaborada pelos autores (2018).

Adicionalmente, 2015, 2014 e 2013 foram os anos que obtiveram maior volume de publicações acerca do tema de Contabilidade Gerencial, conforme evidenciado na Tabela 3. Da mesma forma que nos periódicos classificados como A2, verificou-se que não houve uma evolução constante no número de publicações relativas à área de Contabilidade Gerencial no período analisado.

Analisando a utilização da metodologia de Estudo de Caso, observou-se que, neste grupo de periódicos (B1), foram publicados 66 artigos que abordaram tal metodologia em suas pesquisas, o que representa cerca de $19 \%$ da totalidade de estudos em Contabilidade Gerencial no período avaliado (Tabela 4). 
Análise Bibliométrica das Pesquisas em Contabilidade Gerencial que utilizaram a Estratégia do

Custeio de Caso

Lua Syrma Zaniah Santos, Juliana Ribeiro Souza, Weverton Eugenio Coelho, João Estêvão Barbosa

Neto

Tabela 4

Publicações em periódicos B1 que utilizaram a metodologia de Estudo de Caso

\begin{tabular}{|c|c|c|c|c|c|c|c|c|c|c|c|c|}
\hline Periódico & $\begin{array}{l}\text { Estudo } \\
\text { de Caso }\end{array}$ & 2008 & 2009 & 2010 & 2011 & 2012 & 2013 & 2014 & 2015 & 2016 & & \\
\hline \multirow{2}{*}{$\begin{array}{l}\text { Rev. de Adm. } \\
\text { e Contab.da } \\
\text { Unisinos }\end{array}$} & Único & 2 & 1 & 1 & & 1 & & & & & 5 & \multirow[b]{2}{*}{11} \\
\hline & Múltiplo & 1 & & 1 & 1 & 2 & & 1 & & & 6 & \\
\hline \multirow{2}{*}{$\begin{array}{l}\text { Brazilian } \\
\text { Business } \\
\text { Review }\end{array}$} & Único & & & 1 & & & & & & & 1 & \multirow[b]{2}{*}{1} \\
\hline & Múltiplo & & & & & & & & & & 0 & \\
\hline \multirow{2}{*}{$\begin{array}{l}\text { Contabilidade, } \\
\text { Gestão e } \\
\text { Governança }\end{array}$} & Único & & & & & & & & & & 0 & \multirow[b]{2}{*}{1} \\
\hline & Múltiplo & & & 1 & & & & & & & 1 & \\
\hline \multirow{2}{*}{$\begin{array}{l}\text { Custos } \\
\text { Agronegócios } \\
\text { Online }\end{array}$} & Único & 4 & 4 & 6 & 2 & 2 & 5 & 3 & 4 & 5 & 35 & \multirow{2}{*}{38} \\
\hline & Múltiplo & 1 & & & & 1 & 1 & & & & 3 & \\
\hline \multirow{2}{*}{$\begin{array}{l}\text { Enfoque: } \\
\text { Reflexão } \\
\text { Contábil }\end{array}$} & Único & 2 & & 1 & & & & & & & 3 & \multirow{2}{*}{3} \\
\hline & Múltiplo & & & & & & & & & & 0 & \\
\hline \multirow{2}{*}{$\begin{array}{l}\text { Revista de } \\
\text { contabilidade } \\
\text { e } \\
\text { Organizações }\end{array}$} & Único & & 1 & & & & & 1 & 1 & & 3 & \multirow[b]{2}{*}{4} \\
\hline & Múltiplo & & & & 1 & & & & & & 1 & \\
\hline \multirow{2}{*}{$\begin{array}{ll}\text { Rev. } & \text { de } \\
\text { Contab. } & \text { do } \\
\text { Mestrado } & \text { em } \\
\text { Ciências } & \\
\text { Contábeis } & \text { da } \\
\text { UERJ } & \\
\end{array}$} & Único & & 1 & & & & 1 & & & 1 & 3 & \multirow[b]{2}{*}{3} \\
\hline & Múltiplo & & & & & & & & & & 0 & \\
\hline \multirow{2}{*}{$\begin{array}{l}\text { Rev. de Educ. } \\
\text { e Pesq. em } \\
\text { Contabilidade }\end{array}$} & Único & & & & & & 3 & & & 1 & 4 & \multirow{2}{*}{5} \\
\hline & Múltiplo & & & & & & 1 & & & & 1 & \\
\hline $\begin{array}{ll}\begin{array}{l}\text { Total } \\
\text { artigos }\end{array} & \text { de } \\
\end{array}$ & & 10 & 7 & 11 & 4 & 6 & 11 & 5 & 5 & 7 & & 66 \\
\hline
\end{tabular}

Nota. Fonte: elaborada pelos autores (2018).

Novamente, a Revista Custos e Agronegócios Online e a Revista de Administração e Contabilidade da Unisinos destacaram-se em relação às demais no que tange aos percentuais apresentados. No primeiro caso, mais da metade (58\%) do 
Análise Bibliométrica das Pesquisas em Contabilidade Gerencial que utilizaram a Estratégia do Custeio de Caso

Lua Syrma Zaniah Santos, Juliana Ribeiro Souza, Weverton Eugenio Coelho, João Estêvão Barbosa

total de artigos publicados que aderiram ao Estudo de Caso como metodologia base pertenciam à Revista Custos e Agronegócios Online, enquanto que 19\% foram publicados na Revista de Administração e Contabilidade da Unisinos.

Pode-se inferir, portanto, que os dois periódicos que apresentaram maior volume de publicações em Contabilidade Gerencial foram os mesmos que se utilizaram, em maior grau, da metodologia do Estudo de Caso em suas pesquisas. Complementarmente, apurou-se que os anos 2010 e 2013 se destacaram com um maior número de publicações que adotaram essa metodologia. Porém, não se observou, no período analisado, uma evolução constante no número de publicações que se utilizaram do Estudo de Caso como metodologia de pesquisa.

Em relação aos artigos publicados na área de Contabilidade Gerencial que não empregaram o Estudo de Caso, verificou-se que as metodologias mais empregadas foram abordagem qualitativa, com realização de pesquisas descritivas, documental e utilização de técnicas de levantamento ou survey e entrevistas.

Por fim, destaca-se que os temas mais abordados entre os 66 artigos que adotaram o Estudo de Caso como metodologia nos periódicos classificados como B1 foram Gestão Estratégica de Custos, Orçamento e Balanced Scorecard.

\subsection{Perfil dos artigos publicados em periódicos classificados como B2}

$\mathrm{Na}$ análise dos periódicos classificados como B2, levantou-se um total de 122 artigos (Tabela 5). Os periódicos que mais realizaram publicações foram: Pensar Contábil (20\%); Sociedade, Contabilidade e Gestão (15\%); e a Contextus - Revista Contemporânea de Contabilidade e Gestão (14\%). 
Análise Bibliométrica das Pesquisas em Contabilidade Gerencial que utilizaram a Estratégia do

Custeio de Caso

Lua Syrma Zaniah Santos, Juliana Ribeiro Souza, Weverton Eugenio Coelho, João Estêvão Barbosa

Neto

Tabela 5

Publicações em periódicos B2

\begin{tabular}{|l|c|c|c|c|c|c|c|c|c|c|c|}
\hline \multicolumn{1}{|c|}{ Periódico } & $\mathbf{2 0 0 8}$ & $\mathbf{2 0 0 9}$ & $\mathbf{2 0 1 0}$ & $\mathbf{2 0 1 1}$ & $\mathbf{2 0 1 2}$ & $\mathbf{2 0 1 3}$ & $\mathbf{2 0 1 4}$ & $\mathbf{2 0 1 5}$ & $\mathbf{2 0 1 6}$ & Total & $\%$ \\
\hline $\begin{array}{l}\text { Contextus - Revista } \\
\text { Contemporânea de } \\
\text { Economia e Gestão }\end{array}$ & & & 2 & 1 & 2 & 3 & 4 & & 5 & 17 & $14 \%$ \\
\hline $\begin{array}{l}\text { Desenvolvimento em } \\
\text { questão }\end{array}$ & & & & & & & 1 & 1 & & 2 & $2 \%$ \\
\hline $\begin{array}{l}\text { Sociedade, } \\
\text { Contabilidade e Gestão }\end{array}$ & 2 & 1 & 2 & 2 & 2 & 2 & 3 & 1 & 3 & 18 & $15 \%$ \\
\hline $\begin{array}{l}\text { Revista Contemporânea } \\
\text { de Contabilidade }\end{array}$ & & & & & 4 & 3 & 2 & 5 & 1 & 15 & $12 \%$ \\
\hline Pensar Contábil & 3 & 3 & 3 & 4 & 2 & 4 & 4 & 1 & & 24 & $20 \%$ \\
\hline $\begin{array}{l}\text { E \& G - Revista } \\
\text { Economia e Gestão }\end{array}$ & 1 & & 6 & 2 & 2 & & 1 & 3 & 15 & $12 \%$ \\
\hline Gestão e Planejamento & 2 & & & 4 & 1 & 1 & 3 & & 2 & 13 & $11 \%$ \\
\hline Reunir & & 2 & 2 & & & 1 & & & 5 & $4 \%$ \\
\hline $\begin{array}{l}\text { Pensamento } \\
\text { contemporâneo em } \\
\text { administração }\end{array}$ & 1 & 2 & 1 & & & & 2 & 1 & & 7 & $6 \%$ \\
\hline $\begin{array}{l}\text { Reúna. Revista de } \\
\text { Economia da UNA }\end{array}$ & $7 \%$ & 7 & 10 & 21 & 13 & 18 & 20 & 11 & 14 & $\mathbf{1 2 2}$ & \\
\hline Total de artigos & $8 \%$ & $17 \%$ & $11 \%$ & $15 \%$ & $16 \%$ & $9 \%$ & $11 \%$ & & $100 \%$ \\
\hline$\%$ & & & & & & & & \\
\hline
\end{tabular}

Nota. Fonte: elaborada pelos autores (2018).

Como se constatou nos periódicos classificados como A2 e B1, os periódicos B2 não apresentaram, no período analisado, uma evolução na mesma proporção e direção no número de publicações no campo de Contabilidade Gerencial, sendo 2011 o ano mais profícuo de produção (17\% da amostra total). Porém, observou-se que o número de publicações cresceu no período de 2011 a 2016 se comparado com os anos anteriores.

Analisando os periódicos $\mathrm{B} 2$ em relação à metodologia adotada, constatou-se que 41 artigos, ou seja, 33\% adotaram o Estudo de Caso para a realização das pesquisas, sendo o Estudo de Caso Único a tipologia mais adotada, conforme evidenciado na Tabela 6. 
Análise Bibliométrica das Pesquisas em Contabilidade Gerencial que utilizaram a Estratégia do

Custeio de Caso

Lua Syrma Zaniah Santos, Juliana Ribeiro Souza, Weverton Eugenio Coelho, João Estêvão Barbosa

Tabela 6

Publicações em periódicos B2 que utilizaram a metodologia de Estudo de Caso

\begin{tabular}{|c|c|c|c|c|c|c|c|c|c|c|c|c|}
\hline Periódico & $\begin{array}{c}\text { Estudo } \\
\text { de } \\
\text { Caso }\end{array}$ & 2008 & 2009 & 2010 & 2011 & 2012 & 2013 & 2014 & 2015 & 2016 & Total & $\begin{array}{c}\text { Estudo } \\
\text { de } \\
\text { Casos }\end{array}$ \\
\hline \multirow{2}{*}{$\begin{array}{l}\text { Contextus. } \\
\text { Revista }\end{array}$} & Único & & & & & 1 & 1 & 1 & & 1 & 4 & \multirow{2}{*}{7} \\
\hline & Múltiplo & & & & & & 2 & 1 & & & 3 & \\
\hline \multirow{2}{*}{$\begin{array}{l}\text { Desenvolvimento } \\
\text { em nı อstãn }\end{array}$} & Único & & & & & & & & & & & \multirow{2}{*}{0} \\
\hline & Múltiplo & & & & & & & & & & & \\
\hline \multirow{2}{*}{$\begin{array}{l}\text { Sociedade, } \\
\text { Contabilidade e }\end{array}$} & Único & 1 & & & & & & 1 & & 1 & 3 & \multirow{2}{*}{5} \\
\hline & Múltiplo & & 1 & 1 & & & & & & & 2 & \\
\hline \multirow{2}{*}{$\begin{array}{l}\text { Revista } \\
\text { Contemporânea }\end{array}$} & Único & & & & & 1 & 2 & & 1 & & 4 & \multirow{2}{*}{4} \\
\hline & Múltiplo & & & & & & & & & & & \\
\hline \multirow{2}{*}{ Pensar Contábil } & Único & 1 & 2 & 2 & 2 & & & 1 & 1 & & 9 & \multirow{2}{*}{10} \\
\hline & Múltiplo & 1 & & & & & & & & & 1 & \\
\hline \multirow{2}{*}{$\begin{array}{l}\text { E \&G Revista } \\
\text { Economia } \quad \mathrm{e}\end{array}$} & Único & & & & 1 & 1 & & & & 2 & 4 & \multirow{2}{*}{6} \\
\hline & Múltiplo & & & & 1 & & & & & 1 & 2 & \\
\hline \multirow{2}{*}{$\begin{array}{l}\text { Gestão e } \\
\text { Planeiamentn }\end{array}$} & Único & & & & 1 & 1 & & 1 & & & 3 & \multirow{2}{*}{3} \\
\hline & Múltiplo & & & & & & & & & & & \\
\hline \multirow[t]{2}{*}{ Reunir } & Único & & & & 1 & & & & & & 1 & \multirow[t]{2}{*}{1} \\
\hline & Múltiplo & & & & & & & & & & & \\
\hline \multirow{2}{*}{$\begin{array}{l}\text { Pensamento } \\
\text { contemporâneo }\end{array}$} & Único & & & 1 & & & & & & & 1 & \multirow{2}{*}{1} \\
\hline & Múltiplo & & & & & & & & & & & \\
\hline \multirow{2}{*}{$\begin{array}{l}\text { Reúna. Revista } \\
\text { de Economia da }\end{array}$} & Único & 1 & & & & & & 2 & 1 & & 4 & \multirow{2}{*}{4} \\
\hline & Múltiplo & & & & & & & & & & & \\
\hline Total de artigos & & 4 & 3 & 4 & 6 & 4 & 5 & 7 & 3 & 5 & & 41 \\
\hline
\end{tabular}

Nota. Fonte: elaborada pelos autores (2018).

A revista Pensar Contábil também se destacou como o periódico em que mais se publicam artigos que realizaram Estudos de Caso, sendo essa metodologia adotada em 10 das suas 24 publicações, representando um total de $42 \%$ do total da amostra. Esse periódico foi seguido pela Contextus - Revista contemporânea de Economia e Gestão que publicou 7 artigos que adotaram Estudos de Caso de um total de 17 artigos de 
Análise Bibliométrica das Pesquisas em Contabilidade Gerencial que utilizaram a Estratégia do Custeio de Caso

Lua Syrma Zaniah Santos, Juliana Ribeiro Souza, Weverton Eugenio Coelho, João Estêvão Barbosa

Contabilidade Gerencial.

$\mathrm{O}$ ano em que houve maior número de publicações que adotaram o Estudo de Caso foi 2014, com 7 publicações. No entanto, constatou-se que não existe uma tendência de evolução, durante o período analisado, no número de artigos publicados que empregaram o Estudo de Caso.

Dentre os artigos publicados no campo de Contabilidade Gerencial, aqueles que não adotaram o Estudo de Caso como método de pesquisa utilizaram variados tipos de metodologia. Destacaram-se, entre elas, as pesquisas bibliográfica, documental, descritiva e qualitativa, com emprego de técnicas de levantamento ou survey, entrevistas de análise de conteúdo.

Sob o enfoque dos assuntos abordados pelas publicações dos periódicos classificados como B2, constatou-se que, de forma semelhante aos estudos publicados nos periódicos $\mathrm{A} 2$ e B1, os assuntos relativos à Gestão Estratégica de Custos foram os mais estudados.

\subsection{Perfil geral dos artigos publicados em periódicos nacionais que utilizaram o Estudo de Caso}

A partir das análises realizadas de maneira destacada, é possível traçar um perfil das publicações relativas ao tema da Contabilidade Gerencial nos periódicos nacionais da área Contábil, pertencentes aos três níveis mais bem avaliados pelo Qualis CAPES, excluindo-se periódicos $A 1$, já que não havia periódicos nacionais pertencentes a este nível até o momento de realização desta pesquisa. De forma adicional, pode-se avaliar a utilização da metodologia de pesquisa de Estudo de Caso dentre estes trabalhos, conforme demonstrado nas Tabelas 7 e 8. 
Análise Bibliométrica das Pesquisas em Contabilidade Gerencial que utilizaram a Estratégia do Custeio de Caso

Lua Syrma Zaniah Santos, Juliana Ribeiro Souza, Weverton Eugenio Coelho, João Estêvão Barbosa

Tabela 7

Publicações nos periódicos nacionais na área de Contabilidade Gerencial

\begin{tabular}{|c|c|c|c|c|c|c|c|c|c|c|}
\hline Periódicos/Ano & $\mathbf{2 0 0 8}$ & $\mathbf{2 0 0 9}$ & $\mathbf{2 0 1 0}$ & $\mathbf{2 0 1 1}$ & $\mathbf{2 0 1 2}$ & $\mathbf{2 0 1 3}$ & $\mathbf{2 0 1 4}$ & $\mathbf{2 0 1 5}$ & $\mathbf{2 0 1 6}$ & $\begin{array}{c}\text { Total de } \\
\text { artigos }\end{array}$ \\
\hline A2 & 17 & 11 & 17 & 15 & 12 & 12 & 13 & 7 & 15 & $\mathbf{1 1 9}$ \\
\hline B1 & 36 & 41 & 32 & 35 & 30 & 45 & 46 & 51 & 36 & $\mathbf{3 5 2}$ \\
\hline B2 & 8 & 7 & 10 & 21 & 13 & 18 & 20 & 11 & 14 & $\mathbf{1 2 2}$ \\
\hline Total de artigos & $\mathbf{6 1}$ & $\mathbf{5 9}$ & $\mathbf{5 9}$ & $\mathbf{7 1}$ & $\mathbf{5 5}$ & $\mathbf{7 5}$ & $\mathbf{7 9}$ & $\mathbf{6 9}$ & $\mathbf{6 5}$ & $\mathbf{5 9 3}$ \\
\hline \% & $10 \%$ & $10 \%$ & $10 \%$ & $12 \%$ & $9 \%$ & $13 \%$ & $13 \%$ & $12 \%$ & $11 \%$ & $100 \%$ \\
\hline
\end{tabular}

Nota. Fonte: elaborada pelos autores (2018).

Analisando a Tabela 7, percebe-se que foram 352 periódicos classificados como B1, ou seja, valor 195\% maior que o número de publicações em periódicos A2 e 188\% a mais em relação aos artigos publicados em periódicos classificados como B2. No que se refere à evolução das publicações de forma conjunta entre os periódicos, não foi possível verificar um padrão de crescimento das mesmas, sendo possível, entretanto, verificar que os anos 2014 e 2013 registraram o maior número de publicações nesta análise geral, sendo responsável, cada um, por 13\% das publicações em Contabilidade Gerencial no período investigado.

No entanto, em comparação com os demais periódicos pesquisados neste estudo, os de classificação B1 apresentaram o menor percentual de adoção da metodologia Estudo de Caso em relação ao total de estudos relativos aos assuntos de Contabilidade Gerencial publicados nessa categoria, apesar de apresentar o maior número de estudos na área, quando analisado o total de publicações realizadas no período analisado.

$\mathrm{Na}$ Tabela 8, estão elencadas as publicações nos periódicos nacionais que utilizaram a metodologia de Estudo de Caso. 
Análise Bibliométrica das Pesquisas em Contabilidade Gerencial que utilizaram a Estratégia do Custeio de Caso

Lua Syrma Zaniah Santos, Juliana Ribeiro Souza, Weverton Eugenio Coelho, João Estêvão Barbosa

Tabela 8

Publicações nos periódicos nacionais que utilizaram a metodologia de Estudo de Caso

\begin{tabular}{|c|c|c|c|c|c|c|c|c|c|c|c|c|}
\hline Periódicos & $\begin{array}{c}\text { Estudo } \\
\text { de } \\
\text { Caso }\end{array}$ & 2008 & 2009 & 2010 & 2011 & 2012 & 2013 & 2014 & 2015 & 2016 & $\begin{array}{c}\text { Total } \\
\text { de } \\
\text { artigos }\end{array}$ & $\begin{array}{l}\text { Estudo } \\
\text { de } \\
\text { Casos }\end{array}$ \\
\hline \multirow{2}{*}{$\mathrm{A} 2$} & Único & 3 & 3 & 2 & 2 & 3 & 4 & 3 & 1 & 6 & 27 & \multirow{2}{*}{36} \\
\hline & Múltiplo & 3 & 1 & 1 & 1 & 2 & 1 & 0 & 0 & 0 & 9 & \\
\hline \multirow{2}{*}{ B1 } & Único & 8 & 7 & 9 & 2 & 3 & 9 & 4 & 5 & 7 & 54 & \multirow{2}{*}{66} \\
\hline & Múltiplo & 2 & 0 & 2 & 2 & 3 & 2 & 1 & 0 & 0 & 12 & \\
\hline \multirow{2}{*}{ B2 } & Único & 3 & 2 & 3 & 5 & 4 & 3 & 6 & 3 & 4 & 33 & \multirow{2}{*}{41} \\
\hline & Múltiplo & 1 & 1 & 1 & 1 & 0 & 2 & 1 & 0 & 1 & 8 & \\
\hline \multicolumn{2}{|c|}{ Total de artigos } & 20 & 14 & 18 & 13 & 15 & 21 & 15 & 9 & 18 & & 143 \\
\hline \multicolumn{2}{|c|}{$\%$} & $14 \%$ & $10 \%$ & $13 \%$ & $9 \%$ & $10 \%$ & $15 \%$ & $10 \%$ & $6 \%$ & $13 \%$ & & $100 \%$ \\
\hline
\end{tabular}

Nota. Fonte: elaborada pelos autores (2018).

Em uma abordagem específica em relação ao número total de publicações que adotaram o Estudo de Caso, constata-se que os periódicos B1 publicaram 30 trabalhos a mais do que os de classificação A2 e 25 a mais do que periódicos B2 sobre temas relacionados à Contabilidade Gerencial que fizeram uso de Estudos de Caso.

Adicionalmente, assim como observado de maneira ampla em relação à evolução ou não das publicações no âmbito gerencial-contábil, verifica-se que não houve um padrão de crescimento na adoção da metodologia de Estudo de Caso entre os periódicos estudados.

Apesar dos achados de Faria et al. (2013), ao avaliar o perfil das publicações em Contabilidade Gerencial, em que apontaram que as estratégias mais utilizadas pelos pesquisadores foram a pesquisa bibliográfica e o Estudo de Caso, sendo este último mais usado se comparado à tipologia com o tipo de metodologia empregada, o presente estudo não confirmou a utilização ampla desta metodologia para a amostra utilizada, já que apenas 24\% (143) das publicações avaliadas adotaram o Estudo de Caso como tipologia ou estratégia de pesquisa. A amostra dessa pesquisa é diferente de outros estudos já realizados, fazendo com que os resultados aqui encontrados contribuam para uma maior compreensão do comportamento e do desenvolvimento da 
Análise Bibliométrica das Pesquisas em Contabilidade Gerencial que utilizaram a Estratégia do Custeio de Caso

Lua Syrma Zaniah Santos, Juliana Ribeiro Souza, Weverton Eugenio Coelho, João Estêvão Barbosa

produção do conhecimento na área de Contabilidade Gerencial. Também auxilia no maior aprendizado sobre o posicionamento intelectual da área que está sendo analisada.

Adicionalmente, os achados desta pesquisa coadunam com as constatações de Frezatti et al. (2015), visto que não se observou um crescimento das publicações contábeis-gerenciais nos periódicos brasileiros no período analisado, corroborando a constatação dos autores de que há certa pressão por publicações de melhor qualidade nos últimos anos, o que torna ainda mais complexa a elaboração de Estudos de Casos, que precisam ser realizados de maneira aprofundada, o que poderia, de fato, inibir sua utilização de forma mais efetiva por parte dos pesquisadores. Destarte, Frezatti et al. (2015) chamaram a atenção para o fato de que os temas relativos a orçamento e controle gerencial prevaleciam entre os temas pesquisados na área contábil-gerencial. Neste aspecto, o presente estudo evidenciou que, além dessas temáticas, outras, tais como a gestão estratégica de custos e o Balanced Scorecard, foram incluídas entre as temáticas mais pesquisadas nos periódicos brasileiros na área de Contabilidade Gerencial. Por meio da Tabela 9, podem-se observar os autores que mais publicaram artigos dentro da amostra analisada.

Tabela 9

Autores mais prolíficos

\begin{tabular}{|l|c|c|}
\hline \multicolumn{1}{|c|}{ Nome do Autor } & Instituição & Total de artigos \\
\hline Carlos Eduardo Facin Lavarda & Universidade Federal de Santa Catarina & 8 \\
\hline Marcos Antonio de Souza & Universidade de São Paulo & 5 \\
\hline Marcos Antonio Souza & Universidade do Vale do Rio dos Sinos & 4 \\
\hline Welington Rocha & Alfa Recursos Humanos & 4 \\
\hline Cláudio de Araújo Wanderley & Universidade Federal de Pernambuco & 4 \\
\hline Josir Simeone Gomes & Universidade Unigranrio & 4 \\
\hline
\end{tabular}

Nota. Fonte: elaborada pelos autores (2018). 
Análise Bibliométrica das Pesquisas em Contabilidade Gerencial que utilizaram a Estratégia do Custeio de Caso

Lua Syrma Zaniah Santos, Juliana Ribeiro Souza, Weverton Eugenio Coelho, João Estêvão Barbosa

Entre os anos 2010 e 2016, o autor que mais publicou trabalhos, utilizando-se do Estudo de Caso nos artigos de Contabilidade Gerencial, considerando-se de forma conjunta as três classificações de periódicos examinados, foi Carlos Eduardo Facin Lavarda, com oito publicações, seguido por Marcos Antonio de Souza, que publicou cinco estudos no período, conforme esquematizado na Tabela 9.

Diante dos resultados encontrados, este estudo aplica à realidade dos periódicos nacionais uma análise desta abordagem e permite comparações com os demais estudos sobre a relação entre as publicações em Contabilidade Gerencial e a utilização da metodologia de Estudo de Caso, tal como a pesquisa de Beuren e Hall (2014), que identificaram o perfil dos artigos que utilizaram ou se referiram à estratégia do Estudo de Caso em pesquisas sobre a prática da Contabilidade Gerencial publicados em periódicos internacionais em língua inglesa.

Diferentemente das conclusões da referida pesquisa, não foi possível verificar um crescimento das publicações que aderiram ao Estudo de Caso, dentre os artigos que tratavam de Contabilidade Gerencial, no contexto dos periódicos nacionais, no período abarcado pelo presente estudo, o que também se mostra inconsistente, portanto, ao estudo de Lunkes et al. (2011), que encontraram uma tendência de crescimento das publicações nos primeiros anos de suas análises.

Em suma, este estudo evidenciou resultados que corroboram aspectos que divergem em relação a achados anteriores no domínio das pesquisas que abordam o perfil dos estudos contábeis-gerenciais, tanto para análises nacionais, quanto para internacionais. Como exemplo, têm-se os resultados da pesquisa de Ribeiro e Tavares (2017), que identificou que a Contabilidade Gerencial está em uma fase madura e legitimada no contexto acadêmico internacional. Os autores afirmam isso pelo fato de os temas identificados e abordados por eles possuírem uma diversidade de assuntos que se atrelam e interagem de maneira sistêmica, recorrente e com grande difusão na contabilidade gerencial. 
Análise Bibliométrica das Pesquisas em Contabilidade Gerencial que utilizaram a Estratégia do Custeio de Caso

Lua Syrma Zaniah Santos, Juliana Ribeiro Souza, Weverton Eugenio Coelho, João Estêvão Barbosa

\section{CONSIDERAÇÕES FINAIS}

O presente estudo teve como objetivo identificar as características bibliométricas dos artigos publicados em periódicos nacionais que utilizaram a estratégia de Estudo de Caso em pesquisas na área de Contabilidade Gerencial, no período de 2008 a 2016, publicados em periódicos nacionais classificados como A2, B1 e B2 pelo Qualis CAPES.

Dado que a Contabilidade Gerencial opera no contexto da realidade das organizações, o Estudo de Caso é uma estratégia de pesquisa apropriada para ser utilizada nessa área, pois foca no entendimento do dinamismo presente dentro da realidade, combinando método de coleta com as observações teóricas realizadas (Consoli et al., 2008).

Concluiu-se que os periódicos classificados como B1 abordaram os assuntos relativos à Contabilidade Gerencial em maior volume, se comparados aos demais. Contudo, relativamente ao total de suas publicações, foi o tipo de periódico que menos adotou, em termos percentuais, a estratégia de pesquisa do Estudo de Caso. Destacase, portanto, a pouca utilização dessa metodologia de pesquisa em periódicos nacionais, apesar de suas potencialidades e adequações para os temas contábeisgerenciais. Consoli et al. (2008) concluíram que a falta de rigor metodológico e planejamento da pesquisa com Estudo de Casos reduz as vantagens desse método, o que pode explicar sua discreta utilização por parte dos trabalhos científicos, como apontado neste estudo.

Além disso, constatou-se que a maioria das publicações que adotaram o Estudo de Caso pesquisaram assuntos relativos à Gestão Estratégica de Custos, Sistemas de Controle Gerencial e Balanced Scorecard. Os assuntos explorados de forma esporádica por esses artigos foram: orçamento, incentivos gerenciais, folga orçamentária, preço de transferência e mudanças nas práticas de Contabilidade Gerencial. De forma ampla, observou-se, para o período pesquisado, que não houve evolução na quantidade de 
Análise Bibliométrica das Pesquisas em Contabilidade Gerencial que utilizaram a Estratégia do Custeio de Caso

Lua Syrma Zaniah Santos, Juliana Ribeiro Souza, Weverton Eugenio Coelho, João Estêvão Barbosa

publicações em Contabilidade Gerencial que se utilizaram do Estudo de Caso como estratégia metodológica. Ou seja, não houve crescimento ou diminuição na divulgação desses trabalhos que demonstrasse uma mudança nesses números. Adicionalmente, Carlos Eduardo Facin Lavarda e Marcos Antonio de Souza foram os autores que mais se destacaram no que se refere às publicações contábeis-gerenciais que se valeram da metodologia do Estudo de Caso.

Salienta-se que o presente estudo apresenta limitações no que se refere ao processo de classificação dos artigos, visto que as análises foram realizadas conforme a compreensão dos pesquisadores sobre os assuntos inerentes ao campo de pesquisa em Contabilidade Gerencial, o que pode ocasionar incertezas intrínsecas quanto às classificações.

Como pesquisas futuras, sugere-se a investigação sobre a relação entre a classificação dos periódicos com a adoção ou não da metodologia de estudos de caso em artigos sobre temas de pesquisas relativos à área de Contabilidade Gerencial e, adicionalmente, a utilização de técnicas estatísticas e metodologias diversas a fim de se verificar possíveis diferenças entre os níveis de publicações acerca do assunto entre os periódicos e, inclusive, as possíveis causas para a não adoção do Estudo de Caso como metodologia base em pesquisas na área de Contabilidade Gerencial.

\section{REFERÊNCIAS}

Ahrens, T., \& Dent, J. F. (1998). Accounting and organizations: realizing the richness of field research. Journal of Management Accounting Research, 10(1), 1-39.

Alves M. A. J. (2006). Usos e abusos dos estudos de caso. Cadernos de Pesquisa, 36(129), 637-651.

Beuren, I. M., \& Erfurth, A. E. (2010). Pesquisa em contabilidade gerencial com base no futuro realizada no Brasil. Contabilidade, Gestão e Governança,13(1), 44-58.

Beuren, I. M., \& Hall, R. J. (2014, jan. abr.). Perfil dos artigos que utilizaram a estratégia do estudo de caso em pesquisas sobre a prática da contabilidade gerencial. Revista de Administração, Contabilidade e Economia (RACE), 13(1), 219 -248. 
Análise Bibliométrica das Pesquisas em Contabilidade Gerencial que utilizaram a Estratégia do

Custeio de Caso

Lua Syrma Zaniah Santos, Juliana Ribeiro Souza, Weverton Eugenio Coelho, João Estêvão Barbosa

Neto

Blonkoski, P. R., Antonelli, R. A., \& Bortoluzzi, S. C. (2017, jan. mar.). Contabilidade Gerencial: análise bibliométrica e sistêmica da literatura científica internacional. Pretexto, 18(1), 80-99. doi: 10.21714/pretexto.v18i1.2857.

Cardoso, R. L., Mário, P. C., \& Aquino, A. C. B. (2007). Contabilidade gerencial: mensuração, monitoramento e incentivos. São Paulo, Atlas.

Carvalho, A. J. D., Pierri Junior, M. A., Lunkes, \& R. Gasparetto, V. (2016). Contabilidade Gerencial: um estudo bibliográfico nas principais revistas internacionais de contabilidade. Sociedade, Contabilidade e Gestão, 11(2), 155-174.

Cesar, A. M. R. V. C., \& Antunes, M. T. P. A. (2008). A utilização do método do Estudo de Caso em pesquisas da área de contabilidade. Encontro Nacional da Associação Nacional de Pós-Graduação e Pesquisa em Administração, Rio de Janeiro, RJ, Brasil, 32.

Consoli, M. A., Museti, Scare, M. A., Fava, R., \& Fratantonio, W. A. (2008). Uma discussão sobre a utilização do Estudo de Casos como método de pesquisa em ciências gerenciais. Encontro Nacional da Associação Nacional de Pós-Graduação e Pesquisa em Administração, Rio de Janeiro, RJ, Brasil, 32.

Cruz, A. P. C., Espejo, M. M. S. B., Gassner, F. P., \& Walter, S. A. (2010, abr. jun.). Uma análise do desenvolvimento do campo de pesquisa em contabilidade gerencial sob a perspectiva colaborativa mapeada em redes sociais. Revista Contabilidade Vista \& Revista, 21(2), 95-120.

Drury, C., \& Tayles, M. (1995). Issues arising from surveys of management accounting practices. Management Accounting Review, 6, 267-280.

Faria, P. M. O, Leal, E. A., Soares, M. A., \& Godoi-de-Souza, E. (2013). Pesquisa em contabilidade gerencial no Brasil: um estudo bibliométrico de 2002 a 2012 nos principais periódicos nacionais. Congresso Brasileiro de Custos, Uberlândia, MG, Brasil, 20.

Frezatti, F., Nascimento, A. R., \& Junqueira, E. (2009, jan. abr.). Desenvolvimento da pesquisa em contabilidade gerencial: as restrições da abordagem monoparadigmática de Zimmerman. Revista Contabilidade \& Finanças, 20(49), 6-24.

Frezatti, F., Aguiar, A. B., Wanderley, C. A., \& Malagueño, R. (2015, jan. mar.). A pesquisa em contabilidade gerencial no Brasil: desenvolvimento, dificuldades e oportunidades. Revista Universo Contábil, 11(1), 47-68. doi: 10.4270/RUC.2015103.

Graham, A. (2010). Como escrever e usar estudos de caso para ensino e aprendizagem 
Análise Bibliométrica das Pesquisas em Contabilidade Gerencial que utilizaram a Estratégia do

Custeio de Caso

Lua Syrma Zaniah Santos, Juliana Ribeiro Souza, Weverton Eugenio Coelho, João Estêvão Barbosa

no setor público. (1a ed.). Brasília, ENAP.

Granlund, M. (2001). Towards explaining stability in and around management accounting systems. Management Accounting Research, 12, 141-146.

Green, F. B., \& Amenkhienan, F. E. (1992). Accounting inovations: a cross sectional survey of manufacturing firms. Journal of Cost Management for the Manufacturing Industry, 5(1), 58-64.

Hopwood, A. G. (1983). On trying to study accounting in the context in which it operates. Accounting, Organisations and Society, 8(23), 287-305.

Hopwood, A. G. (2007). Whither accounting research? The Accounting Review, 82(5), 1365-1374.

Ittner, C. D., \& Larcker, D. F. (2001) Assessing empirical research in managerial accounting: a value based management perspective. Journal of Accounting and Economics, 32, 349-410.

Johnson, H. T., \& Kaplan, R. S. (1987). Relevance lost the rise and fall of management accounting. Boston, Harvard Business School Press.

Kaplan, R. S. (1984, jul). The evolution of management accounting. The Accounting Review,59(3), 390-418.

Lopes, A. B., \& Lima, I. S. (2001, mai. jun.). Perspectivas para a pesquisa em contabilidade: o Impacto dos derivativos. Revista Contabilidade \& Finanças, 15(6), 2541.

Lunkes, R. J., Rosa, F. S., Gasparetto, V., \& Baldoino, E. (2011). Análise da produção científica e a formação de doutores em contabilidade gerencial: um estudo no cenário brasileiro. Advances in Scientific and Applied Accounting, 4(3), 361-78.

Marques, K. C. M., Camacho, R. R., \& Alcantara, C. C. V. (2015). Avaliação do rigor metodológico de estudos de caso em Contabilidade Gerencial publicados em periódicos no Brasil. Revista Contabilidade e Finanças, 6(67), 27-42.

Martins, G. A. \& Theófilo, C. R. (2009). Metodologia da investigação científica para ciências sociais aplicadas. (2a ed.). São Paulo, Atlas.

Moraes, R.O, Igarashi, E. T., Camacho, R. R., \& Marques, K. C. M. (2013). Gestão Estratégica de Custos: investigação da produção científica no período de 2008 a 2012. Congresso Brasileiro de Custos, Uberlândia, Minas Gerais, Brasil, 20. 
Nascimento, A. R., Junqueira, E., \& Martins, G. A. (2010, nov. dez.). Pesquisa acadêmica em contabilidade gerencial no Brasil: análise e reflexões sobre teorias, metodologias e paradigmas. Revista de Administração Contemporânea, 14(6), 11131133.

Oliveira, E. K. F, \& Boente, D. R. (2012, jan. jun.). Análise bibliométrica da produção científica recente sobre contabilidade gerencial. Revista Organizações em Contexto, 8(15), 199-212.

Oliveira, S. C. M.; Barbosa, E. S, Rezende, I. C. C., Silva, R. P. A., \& Albuquerque, L. S. (2013). Bibliometria em artigos de contabilidade aplicada ao setor público. Congresso Brasileiro de Custos, Uberlândia, Minas Gerais, Brasil, 20.

Otley, D. T. (1985). Developments in management accounting research. The British Accounting Review, 13, 3-23.

Ribeiro, H. C. M., \& Tavares, V. C. M. (2017). Comportamento e Particularidades da produção acadêmica do tema "Contabilidade Gerencial" divulgada na base de dados do ISI WEB of Science Core Collection de 1985 a 2014. Revista de Educação e Pesquisa em Contabilidade (REPeC), 11(1), 5-29.

Yin, R. K. (2001). Estudo de Caso: planejamento e método. Trad. Daniel Grassi. (2a ed.). Porto Alegre, Bookman.

Zimmerman, J. L. (2001). Conjectures regarding empirical managerial accounting research. Journal of Accounting and Economics, 32, 41-427.

Data de Submissão: 30/04/2018

Data de Aceite: 26/12/2018 